\title{
DE PERTO E DE DENTRO: notas para uma etnografia urbana
}

\section{José Guilherme Cantor Magnani}

\section{Introdução}

Neste artigo pretendo articular duas linhas de reflexão: uma sobre cidade e outra sobre etnografia. O propósito é explorar as possibilidades que esta última, como método de trabalho característico da antropologia, abre para a compreensão do fenômeno urbano, mais especificamente para a pesquisa da dinâmica cultural e das formas de sociabilidade nas grandes cidades contemporâneas. Em primeiro lugar exponho, de forma sumarizada, alguns dos enfoques mais correntes sobre a questão da cidade e, em contraste com estas abordagens, que classifico como um olhar de fora e de longe, apresento outra de cunho etnográfico, a que denomino de olhar de perto e de dentro.

Não se trata, contudo, neste caso, de qualquer etnografia: procuro distinguir a proposta que desenvolvo de outros experimentos que também se apresentam como etnográficos. Penso, ademais, que não há necessidade de muitos malabarismos pós-modernos para aplicar com proveito a etnografia a questões próprias do mundo contemporâneo e da cidade, em particular: desde as primeiras incursões a campo, a antropologia vem desenvolvendo e colocando em prática uma série de estratégias, conceitos e modelos que, não obstante as inúmeras revisões, críticas e releituras (quem sabe até mesmo graças a esse continuado acompanhamento exigido pela especificidade de cada pesquisa) constituem um repertório capaz de inspirar e fundamentar abordagens sobre novos objetos e questões atuais.

Explicito, a seguir, os pressupostos que estão na base dessa proposta e apresento categorias de análise, mostrando a aplicação de algumas delas em pesquisas recentes. Por fim, sinalizo com a perspectiva de um olhar distanciado, indispensável para ampliar o horizonte da análise e complementar a perspectiva de perto e de dentro defendida ao 
longo do artigo. Pretendo, com estas reflexões, contribuir para delimitar, no amplo e vago campo da chamada "antropologia das sociedades complexas", um recorte mais específico, voltado para o estudo de temas própria e especificamente urbanos. ${ }^{1}$

\section{Abordagens sobre a cidade}

Inúmeros são os estudos e as abordagens sobre os rumos e as conseqüências do processo de urbanização em curso, principalmente nas grandes metrópoles contemporâneas. Com o propósito de estabelecer um pano de fundo para melhor destacar a proposta que pretendo desenvolver, inicialmente agrupei tais abordagens, conforme propus em outro texto (Magnani, 1998), em dois blocos: o primeiro deles reúne aquelas análises e respectivos diagnósticos que enfatizam os aspectos desagregadores do processo tais como o colapso do sistema de transporte, as deficiências do saneamento básico, a falta de moradia, a concentração e desigual distribuição dos equipamentos, o aumento dos índices de poluição, da violência. Com base em variáveis e indicadores sociais, econômicos e demográficos, este é o quadro geralmente aplicado às grandes cidades do mundo subdesenvolvido ou, de acordo com o atual eufemismo, dos países emergentes.

Uma outra visão, geralmente referida a metrópoles do primeiro mundo, projeta cenários marcados por uma feérica sucessão de imagens, resultado da superposição e conflitos de signos, simulacros, não-lugares, redes e pontos de encontro virtuais. Esta é a cidade que se delineia a partir da análise de alguns semiólogos, arquitetos, críticos pós-modernos, identificada como o protótipo da sociedade pós-industrial.

No primeiro caso, apresenta-se uma linha de continuidade onde fatores desordenados de crescimento acabam por produzir inevitavelmente $\mathrm{O}$ caos urbano; no segundo, enfatiza-se a ruptura, conseqüência de saltos tecnológicos que tornam obsoletas não só as estruturas urbanas anteriores como as formas de comunicação e sociabilidade a elas correspondentes; o caos, aqui, é semiológico. Um, fruto do capitalismo selvagem; a outra, mais identificada com o capitalismo tardio.
Ainda que por motivos diferentes, essas duas perspectivas - aqui polarizadas para efeito comparativo e de contraste - levam a conclusões semelhantes no plano da cultura urbana: deterioração dos espaços e equipamentos públicos com a conseqüente privatização da vida coletiva, segregação, evitação de contatos, confinamento em ambientes e redes sociais restritos, situações de violência etc.

Não obstante seu esquematismo, esta é uma visão bastante recorrente no discurso da mídia e até em análises mais acadêmicas voltados para a discussão de problemas urbanos: é justamente no estereótipo que reside o sucesso da fórmula. Cabe lembrar, a propósito, o ocorrido com o conhecido urbanista catalão, Jordi Borja, em uma de suas visitas a São Paulo. Convidado a participar de um programa de televisão para falar dos problemas das grandes cidades, foi previamente instruído pelo jornalista: "Quero que o senhor diga como a cidade de São Paulo está mal, uma catástrofe, nada funciona etc.; que diga também como, em geral, as cidades vão mal, com problemas de insegurança, contaminação, falta de moradia, proliferação de bairros marginais, pois em todas as cidades há grandes problemas."

Essa perspectiva, em que pesem seu apelo e rendimento para abarcar todo e qualquer transtorno, de enchentes a situações de risco e violência, passando pela perda de contatos e vínculos mais personalizados, evidentemente não esgota o leque de possibilidades de análise das questões urbanas contemporâneas: há outros recortes em que as diferenças entre determinado tipo de cidades situadas em regiões desenvolvidas e suas congêneres no mundo subdesenvolvido cedem espaço para algumas semelhanças. Esta é a perspectiva, por exemplo, de Jordi Borja, que utiliza o conceito de "cidade mundial"; outros, como Saski Sassen (1998, 1999) preferem a expressão "cidades globais". ${ }^{3}$

Tanto num caso como no outro essa denominação alude ao papel que tais cidades ocupam numa economia altamente interdependente: sedes de conglomerados multinacionais, pólos de instituições financeiras, produtoras e/ou distribuidoras de determinados serviços, informações e imagens, elas constituem os nós da ampla rede que também já é conhecida, num mundo globalizado, como "sistema mundial". Sua influência, desta for- 
ma, faz-se sentir muito além das respectivas fronteiras físico-administrativas e nacionais.

Aqui as questões são de outra ordem: todas essas cidades, num certo plano, assemelham-se não apenas pelas funções que exercem, mas pelos equipamentos e instituições que possibilitam seu exercício Assim, supõe-se que uma "cidade global" seja servida por uma rede de hotelaria de padrão internacional, um sistema de transporte seletivo, sofisticadas agências de serviços especializados, sistemas e empresas de informação de ponta. Saskia Sassen (1999) fala, além da globalização, em "digitalização", para caracterizar o processo que produziu as cidades globais.

Chama a atenção o fato de que essa tecnologia, que permite contato imediato e troca de informações on line, não significou o enfraquecimento das cidades. Sassen, a propósito, distingue dois tipos de informação: de um lado, aquele meramente constituído por dados, esses sim, disponíveis de e para qualquer ponto do mundo, desde que estejam devidamente plugados; e, de outro, o processo de sua interpretação, avaliação e discernimento, que exige atores reais: pessoal qualificado, empresas especializadas dos mais variados serviços como apoio jurídico, consultoria etc., compondo o que a autora chama de "infra-estrutura social para a conectividade global" (idem).

Alguns exemplos logo vêm à mente, como protótipos dessa dinâmica: Nova York, em primeiro lugar, Londres, Tókio e, além disso, numa segunda ordem de grandeza, Los Angeles (Davis, 2001), que resume e concentra as vantagens e os problemas desse tipo de cidade - algumas de cujas características podem ser encontradas em outras metrópoles, ainda que situadas em países menos desenvolvidos. ${ }^{4}$ Barcelona, outro caso bastante difundido de cidade global, exemplifica uma característica particular dessa tipologia: a busca e o investimento numa "marca" local distintiva. Pois, se de um lado supõe-se que essas cidades dispõem de uma infra-estrutura peculiar - o que termina por equalizá-las -, de outro, é fundamental que cada uma apresente um elemento diferencial, de forma a torná-la competitiva na atração de capitais, de mão-de-obra especializada, na realização de eventos internacionais etc.
Essa visão tem como base uma nova forma de planejamento urbano, conhecido por "planejamento estratégico" que, entre outras medidas, prevê parcerias entre o poder público e o setor privado com vistas a projetos de renovação urbana. Uma das propostas mais difundidas dessa visão tem como foco áreas centrais buscando a revitalização de espaços degradados e a recuperação, com novos usos, de edificações e equipamentos "históricos" ou "vernaculares" (Zukin, 2000), de forma a atrair novos moradores, usuários e freqüentadores. Esse processo, conhecido como gentrification (enobrecimento, requalificação), propõe uma nova dinâmica, principalmente para os centros das cidades, pois, além de adequá-los como lugares de consumo, inaugura uma nova modalidade de consumo cultural, isto é, o "consumo do lugar".

Tais propostas são identificadas, por alguns, como parte da tendência "pós-moderna" no urbanismo e na arquitetura; há, entretanto, quem retire do termo pós-modernidade qualquer determinação positiva, por considerá-lo vazio, incapaz de introduzir uma ruptura com relação à sua antecessora, ou seja, a modernidade: tanto uma como outra não seriam alternativas, mas, de acordo com Otília Arantes, "passos unificados de um mesmo processo de ajuste da sociedade às reviravoltas que dá o capitalismo para continuar o que sempre foi, e de cujas metamorfoses a paisagem urbana é a fachada mais visível", (1998, pp. 12-13). A autora tem também uma visão bastante crítica tanto em relação ao fenômeno da globalização, como às propostas de revitalização urbana induzidas por esse processo:

Essa mundialização do capital, para chamar a coisa pelo seu verdadeiro nome, que é econômica, tecnológica, midiática, gera descompassos, segregações, guetos multiculturais e multirraciais, ao mesmo tempo em que desterritorializações anárquicas, crescimentos anômalos e transgressivos [...]. Além do mais, as novas tendências estruturais de crise da regulação social e de desmonte dos Estados nacionais transformam os alegados valores locais em mercadorias a serem igualmente consumidas e recicladas na mesma velocidade em que se move o capital. Em linhas gerais, esse é o nó da renovação urbana em andamento tanto nos países afluentes quanto, com mais razão ainda, na periferia (1998, pp. 187-188). 
Em obra coletiva mais recente (2000), essas críticas são retomadas e acrescidas das análises de Carlos Vainer e Ermínia Maricato. O primeiro volta-se especificamente e com uma leitura mais técnica para o planejamento estratégico, modelo difundido no Brasil por algumas agências multilaterais (BIRD, Habitat) e consultores internacionais, sobretudo catalães, com base na da experiência de Barcelona, já mencionada. ${ }^{5}$

Segundo Vainer, este modelo de planejamento é inspirado em conceitos e técnicas oriundos do planejamento empresarial, e sua adoção pelos governos locais justifica-se pelo fato de as cidades estarem submetidas às mesmas injunções que as empresas. A questão urbana, nessa visão, deve ser lida na chave da competitividade: competir por investimentos de capital, tecnologia e competência gerencial; competir por atração de novas indústrias e negócios; competir por atração de força de trabalho qualificada.

O texto de Ermínia Maricato, mais militante, critica o uso de termos como "cidade global", "cidade mundial" e "planejamento estratégico", os quais qualifica como modismos; em contrapartida, tem um apreciação mais positiva a respeito do planejamento de inspiração modernista, justamente por seu caráter "holístico", como afirma, contraposto à fragmentação da visão pós-moderna. É afirmativa: declara-se em prol de um urbanismo socialmente includente e democrático, propondo uma junção entre "plano de ação" e "orçamento participativo".

Finalmente, nessa mesma linha crítica, cabe citar o trabalho de Ana Cristina Fernandes (2001), para quem as novas políticas públicas voltadas para a valorização do plano local (sejam cidades ou regiões) devem ser pensadas à luz dos interesses de três agentes: organismos multilaterais juntamente com instituições de consultoria internacional, corporações transnacionais e elites locais.

Essa discussão, por sua vez, não é estranha à antropologia. Há autores que enfatizam os efeitos homogeneizadores do sistema mundial sobre culturas locais, também creditando tal influência à "grande narrativa da dominação ocidental", conforme a expressão usada por Marshall Sahlins para designar essa leitura (1997, p. 15). Nesse artigo, o autor mostra, todavia, com base em etnografias recentes, que não há uma só lógica nem uma única direção no fluxo transnacional por onde transitam pessoas, mercadorias e recursos: não poucas vezes esse fluxo termina fortalecendo costumes e instituições tradicionais num dos pólos, aquele constituído pela longínqua aldeia de origem.

Mas o propósito aqui não é discutir a ordem internacional e sim delimitar um campo onde se possam apreciar alternativas de análise voltadas para a dinâmica urbana contemporânea. Por certo a discussão é alentada e há muito mais estudos sobre a realidade das grandes cidades que os apresentados aqui, mas algumas pistas encontradas nos autores escolhidos já permitem estabelecer um contraponto à proposta que será desenvolvida no presente trabalho.

\section{O olhar etnográfico: de perto e de dentro}

Tomando em conjunto esse debate em torno da questão urbana com suas propostas e também críticas que vêm constituindo, desde há algum tempo, a pauta de inúmeros encontros de cúpula e seminários de organizações internacionais e também não governamentais, ${ }^{6}$ podem ser destacados alguns pontos em comum.

Em primeiro lugar, observa-se a ausência dos atores sociais. Tem-se a cidade como uma entidade à parte de seus moradores: pensada como resultado de forças econômicas transnacionais, das elites locais, de lobbies políticos, variáveis demográficas, interesse imobiliário e outros fatores de ordem macro; parece um cenário desprovido de ações, atividades, pontos de encontro, redes de sociabilidade. Quando muito, faz-se referência a alguma performance - arte pública - que parecia ser a única forma de intervenção capaz de alterar ou, ao menos, produzir algum momentâneo estremecimento, para deleite de uns poucos e indiferença da maioria que passa ao largo de tais experimentos, a julgar pela repercussão de alguns deles na cidade de São Paulo.?

A bem da verdade, não é propriamente a ausência de atores sociais que chama a atenção, mas a ausência de certo tipo de ator social e o papel determinante de outros. Em algumas análises, a dinâmica da cidade é creditada de forma direta e imediata ao sistema capitalista; mudanças na paisagem 
urbana, propostas de intervenção (requalificação, reciclagem, restauração), alterações institucionais não passam de adaptações às fases do capitalismo que é erigido, na qualidade de variável independente, como a dimensão explicativa última e total.

Neste caso, quando aparecem atores sociais, são os representantes do capital e das forças do mercado: financistas, agentes do setor imobiliário, investidores privados. Personagens como os "animadores culturais" - consultores, arquitetos, artistas e demais intelectuais - também se fazem presentes mas a serviço dos interesses do capital, como "profissionais caudatários", para usar a expressão empregada por Arantes (1998).

Já os moradores propriamente ditos, que, em suas múltiplas redes, formas de sociabilidade, estilos de vida, deslocamentos, conflitos etc., constituem o elemento que em definitivo dá vida à metrópole, não aparecem, e quando o fazem, é na qualidade da parte passiva (os excluídos, os espoliados) de todo o intrincado processo urbano. ${ }^{8}$ Nas leituras mais militantes, por certo, esses atores são recuperados, mas como sujeitos de estratégias políticas como o orçamento participativo, um "urbanismo socialmente includente", associações de vários tipos etc.

Sem ignorar a contribuição da ação engajada e organizada, no entanto, há uma gama de práticas que não são visíveis na chave de leitura da política (ao menos de uma certa visão de política): é justamente essa dimensão que a etnografia ajuda a resgatar. A incorporação desses atores e de suas práticas permitiria introduzir outros pontos de vista sobre a dinâmica da cidade, para além do olhar "competente" que decide o que é certo e o que é errado e para além da perspectiva e interesse do poder, que decide o que é conveniente e lucrativo.

Finalmente, não obstante terem as cidades globais como o referente para suas análises, alguns desses estudos tomam como pressuposto um tipo de cenário da vida pública ainda preso ao protótipo e a dimensões da cidade da alta Idade Média européia ou mesmo da cidade-estado antiga, cuja centralidade era simbolizada e garantida por algumas instituições que dominavam o espaço público. Ora, num aglomerado contíguo com mais de dez milhões de habitantes, como é o caso da cidade de
São Paulo, não há uma, mas várias centralidades (Frúgoli, 2000) e, em vez de se procurar (em vão) um princípio de ordem que garanta a dinâmica da cidade como um todo, mais acertado é tentar identificar essas diferentes centralidades e os múltiplos ordenamentos que nelas e a partir delas ocorrem.

Pois os atuais grandes centros urbanos não podem ser considerados simplesmente como cidades que cresceram demais - daí suas mazelas e distorções. A própria escala de uma megacidade impõe uma modificação na distribuição e na forma de seus espaços públicos, nas suas relações com o espaço privado, no papel dos espaços coletivos e nas diferentes maneiras por meio das quais os agentes (moradores, visitantes, trabalhadores, funcionários, setores organizados, segmentos excluídos, "desviantes" etc.) usam e se apropriam de cada uma dessas modalidades de relações espaciais.

Para além da nostalgia pela "velha rua moderna" de Berman (1989, p. 162) ou do "balé das calçadas" de Jane Jacobs (1992, p. 50), certamente haveria que se perguntar se o exercício da cidadania, das práticas urbanas e dos rituais da vida pública não teriam, no contexto das grandes cidades contemporâneas, outros cenários: para tanto, é necessário procurá-los com uma estratégia adequada.

É o que se propõe com a antropologia, por meio do método etnográfico. As grandes cidades certamente são importantes para análise e reflexão, não apenas porque integram o chamado sistema mundial e são decisivas no fluxo globalizado e na destinação dos capitais, mas também porque concentram serviços, oferecem oportunidades de trabalho, produzem comportamentos, determinam estilos de vida - e não apenas aqueles compatíveis com o circuito dos usuários "solventes", do grande capital, freqüentadores da rede hoteleira, de gastronomia e de lazer que seguem padrões internacionais.

A presença de migrantes, visitantes, moradores temporários e de minorias; de segmentos diferenciados com relação à orientação sexual, identificação étnica ou regional, preferências culturais e crenças; de grupos articulados em torno de opções políticas e estratégias de ação contestatórias ou propositivas e de segmentos marcados pela exclusão - toda essa diversidade leva a pensar não na fragmentação de um multiculturalismo 
atomizado, mas na possibilidade de sistemas de trocas de outra escala, com parceiros até então impensáveis, permitindo arranjos, iniciativas e experiências de diferentes matizes.

É evidente que não há como negar todos aqueles problemas apontados nos diagnósticos com base em inúmeros e consistentes estudos e comprovados também pela própria experiência do dia-a-dia nas grandes cidades, nem, evidentemente, as injunções dos interesses das grandes corporações transnacionais e das elites locais nos sistemas decisórios sobre o ordenamento urbano e sua influência nas condições de vida da população. Mas a pergunta que ainda paira é: isso é tudo? Este cenário degradado esgota o leque das experiências urbanas? Não seria possível chegar a outras conclusões, desvelar outros planos mudando este foco de análise, de longe e de fora, com base em outros métodos e instrumentos de pesquisa, ${ }^{9}$ como os da antropologia, por exemplo?

É bem verdade que esta disciplina, como se sabe, elaborou seus métodos de investigação a partir principalmente do estudo de sociedades dedicadas à coleta, à caça, à agricultura de subsistência e cujo modo de vida tem como base outras formas de assentamento que não a cidade; por conseguinte, as estratégias da pesquisa etnográfica, à primeira vista, não a credenciariam para deslindar as complexidades da cidade contemporânea, imersa no sistema globalizado.

Entretanto, é também consenso que a antropologia não se define por um objeto determinado: mais do que uma disciplina voltada para o estudo dos povos primitivos ela é, como afirma MerleauPonty, "a maneira de pensar quando o objeto é 'outro' e que exige nossa própria transformação. Assim, também viramos etnólogos de nossa própria sociedade, se tomarmos distância com relação a ela" (1984, pp. 199-200). ${ }^{10}$

Essa questão da "distância" como condição para a análise antropológica, assim como outras, correlatas - a relação sujeito/objeto, colocar-se ou não no lugar do outro, dar vOZ ao nativo, o caráter da participação na observação participante, a autoria do texto etnográfico - já rendeu muita discussão e não será retomada aqui. Mas há um ponto que vale a pena identificar porque tem implicações para o argumento deste artigo: trata-se da natureza, da especificidade do conhecimento proporcionado pelo modo de operar da etnografia e que - de acordo com a hipótese que está sendo trabalhada - permite-lhe captar determinados aspectos da dinâmica urbana que passariam desapercebidos, se enquadrados exclusivamente pelo enfoque das visões macro e dos grandes números.

A revisão de algumas tentativas para "cercar" a especificidade da etnografia pode ser reveladora: Peirano (1995), por exemplo, fala em "resíduos" - certos fatos que resistem às explicações habituais e só vêm à luz em virtude do confronto entre a teoria do pesquisador e as idéias nativas; Goldman (2001) refere-se à "possibilidade de buscar, através de uma espécie de 'desvio etnográfico', um ponto de vista descentrado"; ${ }^{11}$ há que lembrar ainda os "anthropological blues" de Da Matta (1974) e a expressão "experience-near versus experience-distant" usada por Geertz (1983).

À sua maneira - com ênfases diferentes cada uma dessas paráfrases, entre outras, deixam entrever alguns núcleos de significado recorrentes: o primeiro deles é uma atitude de estranhamento e/ou exterioridade por parte do pesquisador em relação ao objeto, a qual provém da influência de sua cultura de origem e dos esquemas conceituais de que está armado e que não é descartada pelo fato de estar em contato com outra cultura e outras explicações, as chamadas "teorias nativas". Na verdade, essa co-presença, a atenção em ambas é que acaba provocando a ambigüidade, a possibilidade de uma solução não prevista, um olhar descentrado, uma saída inesperada.

Por outro lado, essa experiência tem efeitos no pesquisador: ela o "afeta" (Goldman, 2001); "transforma" (Merleay-Ponty, 1984), produz-se "nele" e, no limite, "converte" (Peirano, 1995). O pesquisador não apenas apreende o significado do arranjo do nativo, mas ao perceber esse significado e conseguir descrevê-lo agora nos seus termos (dele, analista), é capaz de atestar sua lógica e incorporá-la de acordo com os padrões de seu próprio aparato intelectual e até mesmo de seu sistema de valores. Segundo Merleau-Ponty, "tratase de construir um sistema de referência onde possam encontrar lugar o ponto de vista do indígena, o do civilizado e os erros de um sobre o outro, construir uma experiência alargada que se torne, 
em princípio, acessível para homens de um outro país e de um outro tempo" (1984, p. 199).

Num nível mais geral essa experiência tem como condição o pressuposto de que ambos, pesquisador e nativo, participam de um mesmo plano: o dos "fenômenos fundamentais da vida do espírito" (Lévi-Strauss, 1971, p. 28). Ambos são dotados dos mesmos processos cognitivos que lhes permitem, numa instância mais profunda, uma comunhão para além das diferenças culturais. Afinal, "as milhares de sociedades que existem ou existiram sobre a superfície da terra são humanas e por esse título participamos delas de maneira subjetiva: poderíamos ter feito parte delas e portanto podemos tentar compreendê-las como se fôsssemos parte delas" (idem, p. 26).

Por último cabe assinalar que o método etnográfico não se confunde nem se reduz a uma técnica; pode usar ou servir-se de várias, conforme as circunstâncias de cada pesquisa; ele é antes um modo de acercamento e apreensão do que um conjunto de procedimentos. Ademais, não é a obsessão pelos detalhes que caracteriza a etnografia, mas a atenção que se lhes dá: em algum momento, os fragmentos podem arranjar-se num todo que oferece a pista para um novo entendimento.

Em suma: a natureza da explicação pela via etnográfica tem como base um insight que permite reorganizar dados percebidos como fragmentários, informações ainda dispersas, indícios soltos, num novo arranjo que não é mais o arranjo nativo (mas que parte dele, leva-o em conta, foi suscitado por ele) nem aquele com o qual o pesquisador iniciou a pesquisa. Este novo arranjo carrega as marcas de ambos: mais geral do que a explicação nativa, presa às particularidades de seu contexto, pode ser aplicado a outras ocorrências; no entanto, é mais denso que o esquema teórico inicial do pesquisador, pois tem agora como referente o "concreto vivido".

Assim, o que se propõe inicialmente com o método etnográfico sobre a cidade e sua dinâmica é resgatar um olhar de perto e de dentro capaz de identificar, descrever e refletir sobre aspectos excluídos da perspectiva daqueles enfoques que, para efeito de contraste, qualifiquei como de fora e de longe.

\section{A proposta de uma etnografia urbana}

A mudança de foco que a perspectiva antropológica possibilita, principalmente em função do método etnográfico, tem a vantagem de evitar aquela dicotomia que opõe, no cenário das grandes metrópoles contemporâneas, o indivíduo e as megaestruturas urbanas.

Essa polarização, presente em algumas das posturas aqui expostas, pontua muitas análises e diagnósticos sobre a cidade contemporânea e pode ser identificada mais claramente nos conhecidos discursos do senso comum sobre despersonalização, massificação, solidão etc., motes muito difundidos e sempre à mão quando se quer discorrer sobre os problemas dos grandes centros urbanos:

Em meio à multidão, o indivíduo está só. Ele cruza diariamente com centenas de pessoas que não conhece. Essas pessoas vivem no mesmo meio, mas não convivem. A mesma metrópole produz as massas e isola o indivíduo. Nesse contexto surgem, especialmente na literatura, temas que questionam a perda dos laços sociais tradicionais e apontam a banalização da vida nas grandes cidades. ${ }^{12}$

Uma afirmação como essa, que evoca vagos "laços sociais tradicionais", mas que passa ao largo das possibilidades e das alternativas que a vida cosmopolita propicia, desconhece a existência de grupos, redes, sistemas de troca, pontos de encontro, instituições, arranjos, trajetos e muitas outras mediações por meio das quais aquela entidade abstrata do indivíduo participa efetivamente, em seu cotidiano, da cidade.

A simples estratégia de acompanhar um desses "indivíduos" em seus trajetos habituais revelaria um mapa de deslocamentos pontuado por contatos significativos, em contextos tão variados como o do trabalho, do lazer, das práticas religiosas, associativas etc. É neste plano que entra a perspectiva de perto e de dentro, capaz de apreender os padrões de comportamento, não de indivíduos atomizados, mas dos múltiplos, variados e heterogêneos conjuntos de atores sociais cuja vida cotidiana transcorre na paisagem da cidade e depende de seus equipamentos. 
Se a perspectiva que classifico de perto e de dentro está associada à etnografia, não é toda proposta de pesquisa com base na antropologia ou referida ao método etnográfico que busca esse tipo de conhecimento. Existe, por exemplo, uma modalidade que caracterizo como de passagem: ela consiste em percorrer a cidade e seus meandros observando espaços, equipamentos e personagens típicos com seus hábitos, conflitos e expedientes, deixando-se imbuir pela fragmentação que a sucessão de imagens e situações produz. O relato final, geralmente na forma de ensaio, termina por expressar essa experiência por meio do uso de metáforas que serão tanto mais sugestivas quanto maior a criatividade do analista e o leque de relações que estabelecer: "hibridização", "porosidades", "territorialidades flexíveis", "não-lugares", "configurações espaço-temporais", "paisagens disjuntivas" e outras.

Sem diminuir a importância das vantagens que essa estratégia de pesquisa pode proporcionar é preciso também estar atento a algumas conseqüências que tal profusão terminológica e a multiplicidade de categorias a elas associadas podem acarretar: quando ainda presas ao plano da metáfora, é possível que terminem duplicando, no texto, a heterogeneidade percebida na experiência inicial. ${ }^{13}$ Um desafio para todos os que têm a cidade contemporânea como tema de estudo é, pois, o de construir modelos analíticos mais econômicos que evitem o risco de se reproduzir, no plano de um discurso interpretativo, a fragmentação pela qual as grandes metrópoles são muitas vezes representadas na mídia, nas artes plásticas, na fotografia e em intervenções artísticas no espaço público. ${ }^{14}$

Em todo caso, em vez de um olhar de passagem, cujo fio condutor são as escolhas e o trajeto do próprio pesquisador, o que se propõe é um olhar de perto e de dentro, mas a partir dos arranjos dos próprios atores sociais, ou seja, das formas por meio das quais eles se avêm para transitar pela cidade, usufruir seus serviços, utilizar seus equipamentos, estabelecer encontros e trocas nas mais diferentes esferas - religiosidade, trabalho, lazer, cultura, participação política ou associativa etc.

Esta estratégia supõe um investimento em ambos os pólos da relação: de um lado, sobre os atores sociais, o grupo e a prática que estão sendo estudados e, de outro, a paisagem em que essa prática se desenvolve, entendida não como mero cenário, mas parte constitutiva do recorte de análise. É o que caracteriza o enfoque da antropologia urbana, diferenciando-o da abordagem de outras disciplinas e até mesmo de outras opções no interior da antropologia.

\section{O pressuposto da totalidade}

Há, entretanto, uma questão prévia: qual seria, na estratégia proposta, a unidade de análise? A cidade em seu conjunto ou cada prática cultural em particular? Ou, nos termos de uma dicotomia mais conhecida, trata-se de antropologia da cidade ou na cidade?

Para introduzir essa questão, convém retomar um ponto comum às abordagens até aqui apresentadas: a maioria dos estudos que classifico como olhar de fora e de longe dá pouca relevância àqueles atores sociais responsáveis pela trama que sustenta a dinâmica urbana; quando aparecem, são vistos através do prisma da fragmentação, individualizados e atomizados no cenário impessoal da metrópole.

Entretanto, contrariamente às visões que privilegiam, na análise da cidade, as forças econômicas, a lógica do mercado, as decisões dos investidores e planejadores, proponho partir daqueles atores sociais não como elementos isolados, dispersos e submetidos a uma inevitável massificação, mas que, por meio do uso vernacular da cidade (do espaço, dos equipamentos, das instituições) em esferas do trabalho, religiosidade, lazer, cultura, estratégias de sobrevivência, são os responsáveis por sua dinâmica cotidiana. Postulo partir dos atores sociais em seus múltiplos, diferentes e criativos arranjos coletivos: seu comportamento, na paisagem da cidade, não é errático mas apresenta padrões.

Partir das regularidades, dos padrões e não das "dissonâncias", "desencontros", "hibridizações" como condição da pesquisa supõe uma contrapartida no plano teórico: a idéia de totalidade como pressuposto. Não se trata, evidentemente, daquela totalidade que evoca um todo orgânico, funcional, sem conflitos; tampouco se trata de uma totalida- 
de que coincide, no caso da cidade, com os seus limites político-administrativos: em se tratando de São Paulo, por exemplo, é impensável qualquer pretensão de etnografia de uma área de $1.525 \mathrm{~km}^{2}$ ocupada por cerca de doze milhões de pessoas. No entanto, renunciar a esse tipo de totalidade não significa embarcar no extremo oposto: um mergulho na fragmentação. Se não se pode delimitar uma única ordem, isso não significa que não há nenhuma; há ordenamentos particularizados, setorizados; há ordenamentos, regularidades.

Uma primeira representação de totalidade, como pressuposto da etnografia, é aquela fornecida pela clássica visão de uma comunidade em que os membros se conhecem, mantém relações face-a-face, estão ligados por padrões de troca interpessoais etc.:

[...] defendo que os conhecimentos dos antropólogos sociais têm uma qualidade especial, devido à área onde exercitam sua imaginação artística. Essa área é o espaço vivo de alguma pequena comunidade de pessoas que vivem juntas em circunstâncias em que a maior parte de suas comunicações diárias depende diretamente da interação. Isto não abrange toda a vida social humana, muito menos abrange toda a história humana. Mas todos os seres humanos gastam grande parte das suas vidas em contextos desta espécie (Leach, 1989, pp. 50-51).

A essa perspectiva podem-se agregar as conhecidas passagens - a de Evans-Pritchard, "da porta da minha barraca podia ver o que acontecia no acampamento ou aldeia" (1978 [1940], p. 20) e a de Malinowski, "no meu passeio matinal pela aldeia, podia observar detalhes íntimos da vida familiar [...]" (1978, p. 21). Não obstante as críticas que receberam de autores pós-modernos, essas imagens permanecem associadas a situações de pesquisa não só no contexto das "sociedades de pequena escala": continuam tentadoras para circunscrever o entorno de uma pesquisa com personagens identificados e conhecidos, no interior de fronteiras bem definidas. Em outro trabalho (Magnani, 2000, p. 20) discuti sua aplicação no cenário das grandes cidades contemporâneas, caracterizando-a justamente com a expressão "a tentação da aldeia".

Mas se um recorte bem estabelecido é condição para o bom exercício da etnografia, a exigência de totalidade vai além dessa necessidade de se po- der contar com o objeto da pesquisa no interior de limites demarcados. Uma incursão pela etnologia indígena pode esclarecer: se uma delimitação espacial concreta - a aldeia, o acampamento, uma porção definida do território, a jusante ou a montante de tal ou qual rio - é imprescindível para fundar a observação etnográfica, outros recortes, contudo, mais amplos, são mobilizados para situar, avaliar, comparar o detalhe das etnografias. Assim, referências como "paisagem amazônica", "terras baixas sulamericanas" e outras, presentes nos textos de etnologia indígena, permitem determinar recorrências e padrões de troca e comunicação mais amplos nos planos da cosmologia, do xamanismo, da mitologia, dos rituais etc.: sem essa passagem corre-se o risco de ficar preso aos estreitos limites de um estudo de caso. A questão da totalidade coloca-se, dessa maneira, em múltiplos planos e escalas.

Uma segunda característica da totalidade como pressuposto da etnografia diz respeito à dupla face que apresenta: de um lado, a forma como é vivida pelos atores sociais e, de outro, como é percebida e descrita pelo investigador.

Numa conhecida passagem da "Introdução à obra de Marcel Mauss", em que Lévi-Strauss mostra de que maneira elementos de natureza muito diferente podem chegar a se articular num fato social, e que só sob esta forma podem ter uma significação global, transformando-se numa totalidade, o autor afirma que a garantia de que tal fato "corresponda à realidade e não seja uma simples acumulação arbitrária de detalhes mais ou menos certos" é que seja conhecido no interior de uma experiência concreta, desde um plano mais social, localizada no tempo e no espaço, até o plano do indivíduo (Lévi-Strauss, in Mauss, 1971, p. 24).

Para ficar no campo da antropologia urbana, quem já estudou terreiros de candomblé, grupos de jovens, escolas de samba, torcidas organizadas de futebol etc. sabe muito bem que nestes e em outros casos análogos há uma totalidade vivamente experimentada tanto como recorte de fronteira quanto como código de pertencimento pelos integrantes do grupo. Tomando como exemplo a categoria de pedaço que expus em outros trabalhos, é também evidente, por parte de seus integrantes, uma percepção imediata, clara, sem nuanças ou ambigüidades a respeito de quem é ou não é do 
pedaço: é uma experiência concreta e compartilhada. O analista, por sua vez, também percebe tal experiência e a descreve: essa modalidade particular de encontro, troca e sociabilidade supõe a presença de elementos mínimos estruturantes que a tornam reconhecível em outros contextos.

Assim, uma totalidade consistente em termos da etnografia é aquela que, experimentada e reconhecida pelos atores sociais, é identificada pelo investigador, podendo ser descrita em seus aspectos categoriais: para os primeiros, é o contexto da experiência, para o segundo, chave de inteligibilidade e princípio explicativo. Posto que não se pode contar com uma totalidade dada $a$ priori, postula-se uma a ser construída a partir da experiência dos atores e com a ajuda de hipóteses de trabalho e escolhas teóricas, como condição para que se possa dizer algo mais que generalidades a respeito do objeto de estudo.

Portanto, aqueles dois planos a que se fez alusão anteriormente - o da cidade em seu conjunto e o de cada prática cultural assignada a este ou àquele grupo de atores em particular - devem ser considerados como dois pólos de uma relação que circunscrevem, determinam e possibilitam a dinâmica que se está estudando.

Para captar essa dinâmica, por conseguinte, é preciso situar o foco nem tão de perto que se confunda com a perspectiva particularista de cada usuário e nem tão de longe a ponto de distinguir um recorte abrangente, mas indecifrável e desprovido de sentido. Em outros termos, nem no nível das grandes estruturas físicas, econômicas, institucionais etc., nem no das escolhas individuais: há planos intermediários onde se pode distinguir a presença de padrões, de regularidades. E para identificar essas regularidades e poder construir, como referência, algum tipo de totalidade no interior da qual seu significado possa ser apreciado, é preciso contar com alguns instrumentos, algumas categorias de análise, como será discutido a seguir.

\section{A família de categorias}

Essas totalidades são identificadas e descritas por categorias que apresentam, conforme já afirmado, um duplo estatuto: surgem a partir do reconhecimento de sua presença empírica, na forma de arranjos concretos e efetivos por parte dos atores sociais, e podem também ser descritas num plano mais abstrato. Neste caso, constituem uma espécie de modelo, capaz de ser aplicado a contextos distintos daquele em que foram inicialmente identificados. São, portanto, resultado do próprio trabalho etnográfico, que reconhece os arranjos nativos mas que os descreve e trabalha num plano mais geral, identificando seus termos e articulando-os em sistemas de relações. A noção de pedaço, por exemplo, supõe uma referência espacial, a presença regular de seus membros e um código de reconhecimento e comunicação entre eles.

Esta, aliás, é a primeira de uma série de categorias que terminaram conformando uma "família" terminológica - pedaço, trajeto, mancha, pórtico, circuito - e surgiu no contexto de uma pesquisa sobre lazer na periferia de São Paulo. ${ }^{15}$

Contrariamente a uma visão corrente, para a qual o lazer era uma questão de pouca relevância no cotidiano dos trabalhadores, o que se constatou por meio da observação de campo foi um amplo e variado leque de usos do tempo livre nos finais de semana dos bairros de periferia: circos, bailes, festas de batizado, aniversário e casamento, torneios de futebol de várzea, quermesses, comemorações e rituais religiosos, excursões de farofeiros, passeios etc. Eram, evidentemente, modalidades simples e tradicionais, que não tinham o brilho e a sofisticação das últimas novidades da indústria do lazer, nem apresentavam conotações políticas ou de classe explícitas, mas estavam profundamente vinculadas ao modo de vida e às tradições dessa população.

Observando mais de perto as regras que presidem o uso do tempo livre por intermédio dessas formas de lazer, verificou-se que sua dinâmica ia muito além da mera necessidade de reposição das forças despendidas durante a jornada de trabalho: representava, antes, uma oportunidade, por meio de antigas e novas formas de entretenimento e encontro, de estabelecer, revigorar e exercitar aquelas regras de reconhecimento e lealdade que garantem uma rede básica de sociabilidade.

Por outro lado, essas modalidades de lazer tampouco constituíam um todo indiferenciado, disponível e desfrutável por todos, de forma alea- 
tória: havia uma ordem. Era possível distinguir, por exemplo, formas de entretenimento características de homens, por oposição às de mulheres; de crianças versus de adultos; de rapazes e moças, e assim por diante.

Tomando como ponto de partida o espaço onde eram praticadas, foi possível distinguir um sistema de oposições cujos primeiros termos são "em casa" versus "fora de casa". No primeiro deles, "em casa", estavam aquelas formas de lazer associadas a ritos que celebram as mudanças significativas no ciclo vital e tinham como referência a família, ou seja, festas de batizado, aniversário, casamento etc. O segundo termo da oposição, "fora de casa", subdividia-se, por sua vez, em "na vizinhança" e "fora da vizinhança". O primeiro englobava locais de encontro e lazer - bares, lanchonetes, salões de baile, salões paroquiais e terreiros de candomblé ou umbanda, campos de futebol de várzea, o circo etc. - que se situavam nos limites da vizinhança. Estavam, portanto, sujeitos a uma determinada forma de controle, do tipo exercido por gente que se conhece de alguma maneira - seja por morar perto, seja por utilizar os mesmos equipamentos, como ponto de ônibus, telefone público, armazém, farmácia, centro de saúde, quadra de esportes, quando disponíveis.

Quando o espaço - ou um segmento dele assim demarcado torna-se ponto de referência para distinguir determinado grupo de freqüentadores como pertencentes a uma rede de relações, recebia o nome de "pedaço":

O termo na realidade designa aquele espaço intermediário entre o privado (a casa) e o público, onde se desenvolve uma sociabilidade básica, mais ampla que a fundada nos laços familiares, porém mais densa, significativa e estável que as relações formais e individualizadas impostas pela sociedade (Magnani, 1998, p. 116).

Uma primeira análise mostrou que essa noção era formada por dois elementos básicos: um de ordem espacial, física - configurando um território claramente demarcado ou constituído por certos equipamentos - e outro social, na forma de uma rede de relações que se estendia sobre esse território.
As características desses equipamentos definidores de fronteiras (bares, lanchonetes, salões, campo de futebol etc.) mostravam que o território assim delimitado constituía um lugar de passagem e encontro. Entretanto, não bastava passar por esse lugar ou mesmo freqüentá-lo com alguma regularidade para ser do pedaço; era preciso estar situado (e ser reconhecido como tal) numa peculiar rede de relações que combina laços de parentesco, vizinhança, procedência, vínculos definidos por participação em atividades comunitárias e desportivas etc. Assim, era o segundo elemento - a rede de relações - que instaurava um código capaz de separar, ordenar e classificar: era, em última análise, por referência a esse código que se podia dizer quem era e quem não era "do pedaço" e em que grau ("colega", "chegado", "xará" etc.).

Essa categoria, nativa, acabou transcendendo o locus de sua aplicação originária e, a partir de um diálogo com outras propostas, como a representada pela oposição rua versus casa de Roberto Da Matta, passou a ser usada para designar um tipo particular de sociabilidade e apropriação do espaço urbano.

Segundo a conhecida fórmula damattiana, têm-se dois planos, cada qual enfeixando de forma paradigmática uma série de atitudes, valores e comportamentos, uma delas referida ao público e, a outra, ao privado. O pedaço, porém, apontava para um terceiro domínio, intermediário entre a rua e a casa: enquanto esta última é o lugar da família, à qual têm acesso os parentes e a rua é dos estranhos (onde, em momentos de tensão e ambigüidade, recorre-se à fórmula "você sabe com quem está falando?" para delimitar posições e marcar direitos), o pedaço é o lugar dos colegas, dos chegados. Aqui não é preciso nenhuma interpelação: todos sabem quem são, de onde vêm, do que gostam e o que se pode ou não fazer.

Desta forma, uma categoria nativa terminou sendo descrita em termos mais formais, o que permitiu experimentar sua aplicação em outros contextos.

Até então o contexto era o bairro na periferia de São Paulo. A questão levantada em Festa no Pedaço, contudo, resultou em novo projeto de pesquisa $^{16}$ e a primeira pergunta foi sobre o que 
aconteceria em outras partes do território urbano - as regiões centrais, por exemplo -, de um modo geral caracterizadas pelo anonimato e pela impessoalidade nas relações e percorridas por gente de várias procedências. Como se estabelecem, aí, as redes de sociabilidade, já não marcadas por relações de vizinhança ou por práticas compartilhadas no horizonte do dia-a-dia?

Não foi difícil reconhecer a existência de pedaços em regiões centrais da cidade, quando se tratava de áreas marcadamente residenciais: a lógica era a mesma. Em outros pontos, porém, usados principalmente como lugares de encontro e lazer, havia uma diferença com relação à idéia original de pedaço: aqui, diferentemente do que ocorria no contexto da vizinhança, os freqüentadores não necessariamente se conheciam - ao menos não por intermédio de vínculos construídos no dia-a-dia do bairro - mas sim se reconbeciam como portadores dos mesmos símbolos que remetem a gostos, orientações, valores, hábitos de consumo e modos de vida semelhantes.

O componente espacial do pedaço, ainda que inserido num equipamento ou espaço de mais amplo acesso, não comporta ambigüidades desde que esteja impregnado pelo aspecto simbólico que lhe empresta a forma de apropriação característica. Um trecho do relatório de pesquisa torna clara essa idéia:

[...] Nessa rua, [24 de maio] destaca-se uma das tantas galerias da região: Centro Comercial Presidente, ocupada por lojas de discos "funk", "disco" e outros ritmos dançantes (Disco Mania Blacks, Truck's Discos), além de outros serviços como cabeleireiros "black" (Gê Curl Wave, Almir Black Power, Gueto Black Power) que reforçam a particular gramática de sua ocupação característica: é um pedaço negro que aglutina rapazes e moças em torno de algumas marcas de negritude como determinada estética, música, ritmo, freqüência a shows e danceterias (Chic Show. Zimbabwe, Skina Club etc.) ("Os Pedaços da Cidade", relatório de pesquisa, p. 52).

Gangues, bandos, turmas, galeras exibem nas roupas, nas falas, na postura corporal, nas preferências musicais - o pedaço a que pertencem. Neste caso, já não se trata de espaço marcado pela moradia, pela vizinhança, mas o "efeito pedaço" continua: venham de onde vierem, o que buscam é um ponto de aglutinação para a construção e o fortalecimento de laços. Quando jovens negros saem de suas casas e dirigem-se a esse seu pedaço localizado no Centro Comercial Presidente ${ }^{17}$ não o fazem, necessariamente, com o objetivo de dar um "trato no visual" ou comprar discos, vão até lá para encontrar seus iguais, exercitar-se no uso dos códigos comuns, apreciar os símbolos escolhidos para marcar as diferenças. É bom estar lá, "rola um papo legal”, fica-se sabendo das coisas... e é assim que essa rede da sociabilidade vai sendo tecida.

Portanto, se a categoria pedaço revelou-se útil para descrever uma forma de sociabilidade em outro contexto que não o de sua origem, no âmbito da vizinhança e do bairro foi preciso, como se viu, proceder a alguns ajustes.

Mas a incursão pelo centro iria mostrar outros padrões de uso e ordenação do espaço. Existe uma forma de apropriação quando se trata de lugares que funcionam como ponto de referência para um número mais diversificado de freqüentadores. Sua base física é mais ampla, permitindo a circulação de gente oriunda de várias procedências e sem o estabelecimento de laços mais estreitos entre eles. São as manchas, áreas contíguas do espaço urbano dotadas de equipamentos que marcam seus limites e viabilizam - cada qual com sua especificidade, competindo ou complementando - uma atividade ou prática predominante. Numa mancha de lazer, os equipamentos podem ser bares, restaurantes, cinemas, teatros, o café da esquina etc., os quais, seja por competição seja por complementação, concorrem para o mesmo efeito: constituir pontos de referência para a prática de determinadas atividades. Já uma mancha caracterizada por atividades ligadas à saúde, por exemplo, geralmente se constitui em torno de uma instituição do tipo âncora - um hospital -, agrupando os mais variados serviços (farmácias, clínicas particulares, serviços radiológicos, laboratórios etc.), e assim por diante.

As marcas dessas duas formas de apropriação e uso do espaço - pedaço e mancha - na paisagem mais ampla da cidade são diferentes. No primeiro caso, em que o fator determinante é 
constituído pelas relações estabelecidas entre seus membros (como resultado do manejo de símbolos e códigos), o espaço como ponto de referência é restrito, interessando mais a seus habitués. Com facilidade muda-se de ponto, quando então se leva junto o pedaços.

A mancha, ao contrário, sempre aglutinada em torno de um ou mais estabelecimentos, apresenta uma implantação mais estável tanto na paisagem como no imaginário. As atividades que oferece e as práticas que propicia são o resultado de uma multiplicidade de relações entre seus equipamentos, edificações e vias de acesso, o que garante uma maior continuidade, transformando-a, assim, em ponto de referência físico, visível e público para um número mais amplo de usuários.

Diferentemente do que ocorre no pedaço, para onde o indivíduo se dirige em busca dos iguais, que compartilham os mesmos códigos, a mancha cede lugar para cruzamentos não previstos, para encontros até certo ponto inesperados, para combinatórias mais variadas. Numa determinada mancha sabe-se que tipo de pessoas ou serviços se vai encontrar, mas não quais, e é esta a expectativa que funciona como motivação para seus freqüentadores.

A cidade, contudo, não é um aglomerado de pontos, pedaços ou manchas excludentes: as pessoas circulam entre eles, fazem suas escolhas entre as várias alternativas - este ou aquele, este $e$ aquele $e$ depois aquele outro - de acordo com uma determinada lógica. Mesmo quando se dirigem a seu pedaço habitual, no interior de determinada mancha, seguem caminhos que não são aleatórios. Está-se falando de trajetos.

O termo trajeto surgiu da necessidade de se categorizar uma forma de uso do espaço que se diferencia, em primeiro lugar, daquele descrito pela categoria pedaço. Enquanto esta última, como foi visto, remete a um território que funciona como ponto de referência - e, no caso da vida no bairro, evoca a permanência de laços de família, vizinhança, origem e outros -, trajeto aplica-se a fluxos recorrentes no espaço mais abrangente da cidade e no interior das manchas urbanas. É a extensão e, principalmente, a diversidade do espaço urbano para além do bairro que colocam a necessidade de deslocamentos por regiões distantes e não contíguas: esta é uma primeira aplicação da categoria: na paisagem mais ampla e diversificada da cidade, trajetos ligam equipamentos, pontos, manchas, complementares ou alternativos.

Outra aplicação é no interior das manchas. Tendo em vista que elas supõem uma presença mais concentrada de equipamentos, cada qual concorrendo, à sua maneira, para a atividade que lhe dá a marca característica, os trajetos, nelas percorridos, são de curta extensão, na escala do andar: representam escolhas ou recortes no interior daquela mancha, entendida como uma área contígua.

Assim, a idéia de trajeto permite pensar tanto uma possibilidade de escolhas no interior das manchas como a abertura dessas manchas e pedaços em direção a outros pontos no espaço urbano e, por conseqüência, a outras lógicas. Sem essa abertura corre-se o risco de cair numa perspectiva reificadora, restrita e demasiadamente "comunitária" da idéia de pedaço - com seus códigos de reconhecimento, laços de reciprocidade, relações face-a-face. Afirmou-se que pedaço é aquele espaço intermediário entre a casa (o privado) e o público ou, para utilizar um sistema de oposições já consagrado, entre casa e rua. Não é, contudo, um espaço fechado e impermeável a uma e outra, ao contrário. É a noção de trajeto que abre o pedaço para fora, para o âmbito do público.

Os trajetos levam de um ponto a outro por meio dos pórticos. Trata-se de espaços, marcos e vazios na paisagem urbana que configuram passagens. Lugares que já não pertencem à mancha de cá, mas ainda não se situam na de lá; escapam aos sistemas de classificação de uma e outra e, como tal, apresentam a "maldição dos vazios fronteiriços". ${ }^{18}$ Terra de ninguém, lugar do perigo, preferido por figuras liminares e para a realização de rituais mágicos - muitas vezes lugares sombrios que é preciso cruzar rapidamente, sem olhar para os lados...

Há, por fim, a noção de circuito. Trata-se de uma categoria que descreve o exercício de uma prática ou a oferta de determinado serviço por meio de estabelecimentos, equipamentos e espaços que não mantêm entre si uma relação de contigüidade espacial, sendo reconhecido em seu conjunto pelos usuários habituais: por exemplo, o circuito gay, o circuito dos cinemas de arte, o circuito neo-esotérico, dos salões de dança e shows 
black, do povo-de-santo, dos antiquários, dos clubblers e tantos outros.

Retomando, para melhor diferenciar: ainda que pedaço e mancha tenham em comum uma referência espacial bem delimitada, a relação do pedaço com o espaço é mais transitória, pois pode mudar-se de um ponto a outro sem se dissolver, já que seu outro componente constitutivo é o simbólico, em razão da forte presença de um código comum. Já a mancha - delineada pelos equipamentos que se complementam ou competem entre si no oferecimento de determinado bem ou serviço - apresenta uma relação mais estável com o espaço e é mais visível na paisagem: é reconhecida e freqüentada por um círculo mais amplo de usuários.

A noção de circuito também designa um uso do espaço e de equipamentos urbanos possibilitando, por conseguinte, o exercício da sociabilidade por meio de encontros, comunicação, manejo de códigos -, porém de forma mais independente com relação ao espaço, sem se ater à contigüidade, como ocorre na mancha ou no pedaço. Mas tem, igualmente, existência objetiva e observável: pode ser levantado, descrito e localizado.

Em princípio, faz parte do circuito a totalidade dos equipamentos que concorrem para a oferta de tal ou qual bem ou serviço, ou para o exercício de determinada prática, mas alguns deles acabam sendo reconhecidos como ponto de referência e de sustentação à atividade. Mais do que um conjunto fechado, o circuito pode ser considerado um princípio de classificação. Nesse sentido, é possível distinguir um circuito principal que engloba outros, mais específicos: o circuito dos acupunturistas ou o dos astrólogos, por exemplo, fazem parte do circuito principal neo-esotérico e com ele mantém contatos, vínculos e trocas.

Por outro lado, o circuito comporta vários níveis de abrangência e a delimitação de seu contorno depende das perguntas colocadas pelo pesquisador. O povo-de-santo na cidade, como mostrou Rita de Cássia Amaral (2000), tem seu circuito e seu modo de vida, mas é possível, por exemplo, dependendo dos objetivos da pesquisa, delimitar e considerar apenas o circuito das casas africanizadas, ou estendê-lo para as de- mais, incluindo ou não os terreiros de ascendência angola e até os de umbanda; saindo do terreno propriamente religioso, o circuito pode abranger a capoeira, as escolas de samba, os afoxés e também escolas de dança, exposições de arte africana, restaurantes, e assim por diante.

Em cada um desses recortes está-se em contato com o mesmo sistema simbólico e de trocas - continua sendo o universo do povo-de-santo mas a cada ampliação (ou redução) do âmbito, sem que se perca a referência com um campo reconhecido pelos usuários, está-se trabalhando com questões diferentes, definidas de acordo com os propósitos, as perguntas e a literatura acionada da pesquisa.

As aplicações a outros temas de pesquisa podem multiplicar-se: assim, na minha pesquisa sobre neo-esoterismo urbano (Magnani, 1999), tema em que a fragmentação parecia ser a norma, pude descrever vários circuitos derivados do circuito neo-esotérico principal. Um deles é o circuito do xamanismo urbano (idem, 2000) que pode incluir xamãs indígenas, psicólogos, terapeutas corporais, ayahuasqueiros, fitoterapeutas e, com relação aos espaços, articula consultórios na cidade com sítios nos arredores da capital paulistana (para os rituais) e contatos em outras regiões do país (Chapada Diamantina, dos Veadeiros etc.) e do exterior.

Rosani Rigamonte (2001) mostrou que a cultura nordestina na cidade de São Paulo se apóia num circuito que inclui não apenas as conhecidas Casas do Norte e os forrós tradicionais, mas também pequenas cidades do interior baiano como Piripá, Barrinha, Condeúba, as quais, entre outras, recebem considerável revoada de nordestinos já morando em São Paulo por ocasião das festas juninas. Sua inclusão no circuito não se dá como uma referência distante e nostálgica, mas como pólo efetivo num sistema de trocas de longo alcance, pois envolve, ademais, um particular mecanismo de envio de cartas, dinheiro e bens de consumo durante todo o ano, por meio de uma rede paralela de transporte. Seu ponto de partida e chegada é uma praça na zona norte da capital, a praça Silvio Romero que, nas manhãs de domingo, transforma-se num pedaço nordestino, freqüentada por quem pretende en- 
viar encomendas a seus familiares ou deles espera alguma notícia.

Bruna Mantese, em sua pesquisa sobre os straight edge, mostra que o circuito desse segmento da cena punk hardcore estabelece uma conexão com o dos Hare Krishna e que, em vez de essa aproximação servir como exemplo de mais uma "dissonância" na metrópole, apresenta um consistente padrão de troca, com base num interesse comum (ainda que por motivações diferentes, religiosas num caso, políticas em outro) entre esses dois grupos, aparentemente tão distantes: o vegetarianismo. ${ }^{19}$

Este é, pois, um procedimento que permite encarar o problema do "caos semiológico", aquela impressão que se tem cada vez que se isola um determinado indivíduo confrontando-o diretamente com a cidade; nessas condições, é inevitável a sensação de anonimato, fragmentação, desordem. Essa impressão, como já foi dito, é o efeito de um olhar de longe e de fora; ajustando-se devidamente o foco da análise, contudo, é possível perceber os diferentes circuitos que o usuário reconhece e percorre ao estabelecer seus próprios trajetos, seja nos planos profissional, do lazer, do consumo, das práticas devocionais, das estratégias de sobrevivência e participação e muitos outros.

\section{Conclusão}

Como propósito mais geral, este trabalho postulava que a antropologia tinha uma contribuição específica para o entendimento das questões urbanas contemporâneas, diferenciando-se, por meio do enfoque etnográfico, das abordagens de outras perspectivas e disciplinas. Essa proposta previa também uma delimitação no amplo e vago campo conhecido como "antropologia das sociedades complexas", reservando a denominação de antropologia urbana stricto sensu para o estudo de grupos sociais e suas práticas quando propriamente inscritos na trama da cidade, isto é, articulados na e com a paisagem, equipamentos ou instituições urbanas, considerados não um mero cenário, mas uma parte constitutiva dessas práticas.

Trata-se de uma primeira aproximação à complexidade da dinâmica urbana contemporâ- nea: nesse plano, a unidade de análise da antropologia urbana seria constituída pelas diferentes práticas e não pela cidade como uma totalidade ou uma forma específica de assentamento, configurando o que se entende antes por antropologia na cidade e não - ao menos não ainda - como uma antropologia $d a$ cidade.

Para identificar essas práticas e seus agentes, foi proposta uma estratégia que recebeu a denominação de um olhar de perto e de dentro, em contraste com visões que foram classificadas como de fora e de longe. Ao partir dos próprios arranjos desenvolvidos pelos atores sociais em seus múltiplos contextos de atuação e uso do espaço e das estruturas urbanas, este olhar vai além da fragmentação que, à primeira vista, parece caracterizar a dinâmica das grandes cidades e procura identificar as regularidades, os padrões que presidem o comportamento dos atores sociais. Supõe recortes bem delimitados que possibilitam o costumeiro exercício da cuidadosa descrição etnográfica.

Identificar essas práticas significa que o recorte escolhido faz sentido tanto para os próprios atores como para o analista: trata-se de uma totalidade empiricamente definida, mas que, capaz de ter os elementos que os estruturam reconhecíveis como padrões, pode ser descrita, formalizada, constituindo um modelo mais geral. Aponta para uma lógica que transcende o contexto original, com poder descritivo e explicativo.

Desenvolvi algumas categorias que descrevem as formas como podem se apresentar alguns desses recortes na paisagem urbana - pedaço, mancha, trajeto, circuito - procurando mostrar as possibilidades que abrem para identificar diferentes situações da dinâmica cultural e da sociabilidade na metrópole: a noção de pedaço evoca laços de pertencimento e estabelecimentos de fronteiras, mas pode estar inserida em alguma mancha, de maior consolidação e visibilidade na paisagem; esta, por sua vez, comporta vários trajetos como resultado das escolhas que propicia a seus freqüentadores. Já circuito, que aparece como uma categoria capaz de dar conta de um regime de trocas e encontros no contexto mais amplo e diversificado da cidade (e até para fora dela), pode englobar pedaços e trajetos particularizados. 
Como se vê, essas categorias não se excluem e são justamente as passagens e articulações entre seus domínios que permitem levar em conta, no recorte da pesquisa, as escalas das cidades e os diferentes planos da análise. Elas constituem uma gramática que permite classificar e descrever a multiplicidade das escolhas e os ritmos da dinâmica urbana não centrados na escolhas de indivíduos, mas em arranjos mais formais em cujo interior se dão essas escolhas.

As grandes metrópoles contemporâneas não podem ser vistas simplesmente como cidades que cresceram demais e desordenadamente, potencializando fatores de desagregação. Elas também propiciaram a criação de novos padrões de troca e de espaços para a sociabilidade e para os rituais da vida pública. De pouco vale generalizar o desaparecimento da velha rua, tida como símbolo por antonomásia do espaço público, nem se limitar a proclamar que sua função foi ocupada pelas "tiranias da intimidade" ou por zonas desprovidas de sociabilidade: se em determinados contextos ficou inviável como suporte de antigos usos, a experiência da vida pública a que está associada pode ser encontrada em novos arranjos. Um determinado segmento do circuito de lazer, articulando pontos distantes na cidade, é tão real e significativo para seus usuários, quanto a vizinhança no contexto do bairro.

No entanto, cabe reafirmar, por fim, que a meta é seguir em busca de uma lógica mais geral. Do olhar de perto e de dentro, próprio da etnografia, para um olhar distanciado, em direção, aí sim, a uma antropologia $d a$ cidade, procurando desvelar a presença de princípios mais abrangentes e estruturas de mais longa duração. É somente por referência a planos e modelos mais amplos que se pode transcender, incorporando-o, o domínio em que se movem os atores sociais, imersos em seus próprios arranjos, ainda que coletivos.

\section{NOTAS}

1 Este artigo tem como base uma comunicação que apresentei no I Ciclo de Seminários do Centro de Estudos da Metrópole, em agosto de 2001 no Cebrab, São Paulo, e o Relatório "Os caminhos da metrópole", apresentado ao CNPq no final de um pe- ríodo de pesquisa com bolsa PQ (2001). Agradeço a Piero Leirner, Rita de Cássia Amaral e Luiz Henrique de Toledo, do Núcleo da Antropologia Urbana (NAU), pela leitura da primeira versão, comentários e sugestões.

2 Borja, (1995, p. 11). Prossegue o depoimento: [...] "Respondi-lhe: sim, é verdade, mas interessa-me mais ver que tipo de respostas é possível dar a esses problemas. Então já não lhe interessou a entrevista e a desmarcou. Já estávamos esperando na porta do estúdio para começar e mesmo assim a desmarcou" [tradução minha].

3 Outro conceito afim é o de "cidades-regiões globais”. Cf. Scott, J. Allen et al., 2001.

4 Ver, por exemplo, o contraponto feito por Caldeira (2000) entre Los Angeles e São Paulo. Marques e Torres (2000), entretanto, discutem a pertinência da aplicação da categoria "cidade global" ao caso de São Paulo e sua posição relativa no sistema mundial de cidades.

5 Integram o grupo dos catalães, entre outros, Jordi Borja e Manuel de Forn e, em certa medida, também Manuel Castells.

6 Entre outros, a Eco 92, no Rio de Janeiro, e a Habitat II, realizada em Istambul, Turquia, de 4 a 14 de junho de 1996. Em São Paulo podem ser citados o encontro em que Jordi Borja proferiu a conferência La Ciudad Mundial, o "Encontro Centro XXI" organizado pela Associação Viva o Centro (São Paulo), em 1994, como etapa preparatória para o Seminário Internacional Centro XXI. E "Cultura e cidade: Seminário Brasil-Alemanha”, realizado no Instituto Goethe de São Paulo, de 7 a 9 de junho de 2000, que contou com a participação de pesquisadores da USP, Unicamp, UNB e, entre as instituições alemãs, a Universidade de Hannover, a Universidade de Berlim e a Fundação Bauhaus.

7 Foi muito festejada, na mídia, a intervenção com raio laser no Viaduto do Anhangabaú, por ocasião de uma das etapas do projeto "Arte e cidade" , em 1996, e que, por alguns segundos, projetava a imagem do transeunte num imenso painel, dando-lhe momentâneo destaque, retirando-o do "anonimato da multidão". Ora, bastaria acompanhar um pouco mais esse mesmo transeunte em seu trajeto para perceber a rede de relações (trabalho, devoção, lazer, vizinhança etc.) a que está integrado.

8 Note-se que mesmo na análise de Sharon Zukin, o "vernacular" é, por definição, o elemento dominado da paisagem, sempre modelada pelas instituições detentoras do poder (2000, p. 84).

9 Cabe aqui mais um esclarecimento: a escolha deste enfoque não significa descartar estratégias e mode- 
los de análise abrangentes sobre a cidade com base em técnicas de pesquisa que privilegiam dados quantitativos, documentais etc; ao contrário, penso que são complementares e o foco aqui proposto ganha outra dimensão quando aliado às conclusões de estudos conduzidos com outras metodologias, levando-se em conta as questões que só podem ser levantadas por eles.

10 O termo que Merleau-Ponty usa é, na realidade, "etnologia”; é ainda comum, em determinados contextos, a intercambiabilidade entre antropologia, etnologia e etnografia. As distinções entre esses termos variam e dependem de uma série de injunções, desde as acadêmico-institucionais até as de tradições nacionais. Lévi-Strauss vincula a etnografia ao trabalho de campo e a um recorte mais delimitado do objeto de estudo, associando etnologia e antropologia ao estabelecimento de sínteses sucessivamente mais abrangentes. No entanto, afirma que "etnografia, etnologia e antropologia não constituem três disciplinas diferentes, ou três concepções dos mesmos estudos. São, de fato, três etapas ou três momentos de uma mesma pequisa e a preferência por este ou aquele destes termos exprime somente uma atenção predominante voltada para um tipo de pesquisa que não poderia nunca ser exclusiva dos dois outros" (Lévi-Strauss, 1991 [1954], p. 396).

11 "Creio que uma outra possibilidade para a 'antropologia das sociedades complexas' é manter o foco tradicional da disciplina nas instituições centrais da sociedade estudada e buscar, através de uma espécie de "desvio etnográfico", um ponto de vista descentrado. No caso da política, tratar-se-ia de encarar as representações nativas sobre os processos políticos dominantes como verdadeiras teorias políticas produzidas por observadores suficientemente deslocados em relação ao objeto para que possam produzir visões realmente alternativas às dominantes, e de usar tais representações e teorias como guias para a análise antropológica" (2001, p. 7). Essa preocupação, no campo antropológico, com o estudo das instituições centrais da sociedade, começa a sedimentar reflexões mais sistemáticas, como ocorre no NUAP, Núcleo de Antropologia da Política, e também no NAU (Núcleo de Antropologia Urbana da USP); para este último caso, cf. Bevilaqua e Leirner (2000).

12 Trecho do editorial "Uma rede de solidão", Folha de S. Paulo, 20 de fevereiro de 2000.

13 Ver, a propósito, a análise de Ulf Hannerz (1997) sobre três metáforas - fluxos, fronteiras e híbridos na antropologia que denomina de "transnacional", voltada para os estudos sobre a globalização. Para uma polarização de dois estilos de etnografia, ver a contraposição feita por Geertz (2001) entre Pierre Clastres e James Clifford.
14 Cabe, contudo, uma ressalva: o fato de esta proposta empregar uma estratégia de pesquisa que implica deambular, deixando-se impregnar pelo "efeito fragmentação", não significa que a caminhada como tal deva ser descartada como técnica para o recolhimento de um determinado tipo de dados; ao contrário, ela constitui valioso recurso para um primeiro levantamento da paisagem e seu entorno no quais o objeto de estudo está inserido e com os quais mantém vínculos.

15 Neste item retomo as categorias elaboradas à medida que se avançava a pesquisa sobre a cidade, desde Festa no pedaço (1984); alguns trechos foram aproveitados de artigos e livros já publicados.

16 Esse projeto foi denominado "Os pedaços da cidade " e foi desenvolvido entre 1989 e 1990 na cidade de São Paulo, com apoio do CNPq e a participação dos integrantes do Núcleo de Antropologia Urbana tanto na fase de coleta de dados como nas discussões que se seguiam às idas a campo.

17 Ao lado do Teatro Municipal, no centro da cidade e que abriga também um pedaço de roqueiros ligados à cena hardcore.

18 Cf. C. N. Santos e A. Vogel (orgs.), 1985, p. 103, aludindo à expressão the curse of border vacuums, título de um dos capítulos de Jacobs (1992, p. 257).

19 "O Movimento Straight Edge em São Paulo: metrópole, identidades e apropriações urbanas", Projeto de Iniciação Científica (PIBIC/USP/CNPq), agosto/2001 a julho/2002. Como a pesquisa vem revelando, de pouco vale apenas classificar esse grupo como mais uma "tribo urbana"; descrever seu circuito significa identificar e explorar todas as suas conexões e sistemas de troca que, além da assinalada acima, envolve, por exemplo, contatos com grupos de estudo e ação anarquistas.

\section{BIBLIOGRAFIA}

AMARAL, Rita de Cássia. (2000), "O povo de santo (e outros povos) comemora em São Paulo", in J. Guilherme Magnani \& Lilian Torres, Na metrópole: textos de antropologia urbana, São Paulo, Edusp/Fapesp.

ARANTES, Otília. (1998), Urbanismo em fim de linha. São Paulo, Edusp.

BERMAN, Marshal. (1989), Tudo que é sólido desmancha no ar. São Paulo, Companhia das Letras. 
BEVILAQUA, Ciméa \& LEIRNER, Piero. (2000), "Notas sobre a análise antropológica de setores do Estado brasileiro". Revista de Antropologia, 43 (2).

BORJA, Jordi. (1995), "La ciudad mundial", in Memória do Encontro Centro XXI - Anais, São Paulo, Associação Viva o Centro.

CALDEIRA, Teresa. (2000), Cidade de muros. São Paulo, Editora 34.

DAVIS, Mike. (2001), Ecologia do medo. São Paulo, Record.

DA MATTA, Roberto. (1974), "O ofício do etnólogo, ou como ter 'anthropological blues'". Cadernos do PPGAS, Rio de Janeiro, Museu Nacional.

EVANS-PRITCHARD, E. E. (1978), Os Nuer. São Paulo, Perspectiva.

FERNANDES, Ana Cristina. (2001), "Da reestruturação corporativa à competição entre cidades: lições urbanas sobre os ajustes de interesses globais e locais no capitalismo contemporâneo". Espaço \& Debates, 41, ano XVII.

FRÚGOLI, Heitor. (2000), Centralidade em São Paulo. São Paulo, Edusp.

GEERTZ, Clifford. (2001), Nova luz sobre a antropologia. Rio, Jorge Zahar.

(1983), Local knowledge. Nova York, Basic Books.

GOLDMAN, Márcio. (2000), Do ponto de vista não-nativo: sobre a incompreensão antropológica ou os tambores dos mortos e os tambores dos vivos. Comunicação apresentada no seminário temático "A Antropologia e seus Métodos: o Arquivo, o Campo, os Problemas", XXV Encontro Anual da Anpocs, Caxambu.

HANNERS, Ulf. (1997), "Fluxos, fronteiras, híbridos: palavras chave da antropologia transnacional". Mana, 3 (1).

JACOBS, Jane. (1992), The death and life of great American cities. Nova York, Vintage Books, Random House Inc.
LEACH, Edmund. (1989), A diversidade da antropologia. Lisboa, Edições 70.

LÉVI-STRAUSS, Claude. (1971), "Introducción a la obra de Marcel Mauss", in Marcel Mauss, Sociologia y antropologia, Madrid, Editorial Tecnos.

(1991), Antropologia estrutural. Rio de Janeiro, Tempo Brasileiro.

MAGNANI, J. Guilherme. (1998), Festa no pedaço: cultura popular e lazer na cidade. São Paulo, Hucitec [1 ed., Brasiliense, 1984].

(1998), "Transformações na cultura urbana das grandes metrópoles", in A. S. Moreira, Sociedade global: cultura e religião, Petrópolis, Vozes.

(1999), Mystica urbe: um estudo antropológico sobre o circuito neo-esotérico na metrópole. São Paulo, Studio Nobel.

MAGNANI, J. Guilherme \& TORRES, Lilian. (2000), Na metrópole: textos de antropologia urbana. São Paulo, Edusp/Fapesp.

MALINOWSKI, Bronislaw. (1978), Argonautas do pacífico ocidental. São Paulo, Abril Cultural, coleção Os Pensadores.

MARICATO, Ermínia. (2000), "As idéias fora do lugar e o lugar fora das idéias", in Otília Arantes; Carlos Vainer \& Ermínia Maricato, A cidade do pensamento único, Petrópolis, Vozes.

MARQUES, Eduardo \& TORRES, Haroldo. (2000), "São Paulo no contexto do sistema mundial de cidades". Novos Estudos Cebrap, 56, mar.

MERLEAU-PONTY, Maurice. (1984), "De Mauss a Claude Lévi-Strauss". Textos Selecionados, São Paulo, Editora Abril Cultural, coleção Os Pensadores.

PEIRANO, Mariza. (1995), A favor da etnografia. Rio de Janeiro, Relume-Dumará.

RIGAMONTE, Rosani. (2001), Sertanejos contemporâneos: entre a metrópole e o sertão. São Paulo, Humanitas/Fapesp. 
SAHLINS, Marshall. (1997), "O 'pessimismo sentimental' e a experiência etnográfica: porque a cultura não é um 'objeto' em via de extinção". Mana, 3 (1 e 2).

SANTOS, Carlos Nelson \& VOGEL, Arno (orgs.). (1985), Quando a rua vira casa. Rio de Janeiro, Ibam/Finep, Projeto.

SASSEN, Saskia. (1998), As cidades na economia mundial. São Paulo, Studio Nobel.

. (1998), "Megalópoles serão capitais globais", entrevista in www.estado.com. br., 29 set.

(1999), "O renascimento das cidades na era da nova economia", in Entrevistas com especialistas em management e tendências de tecnologia desde 1995, /www.janelanaweb.com/index.html.

SCOTT, Allen J. et al. (2001), "Cidades-regiões globais". Espaço \& Debates, 41, ano XVII.

VAINER, Carlos B. (2000), "Pátria, empresa e mercadoria: notas sobre a estratégia discursiva do planejamento estratégico urbano", in Otília Arantes; Carlos Vainer \& Ermínia Maricato, A cidade do pensamento único, Petrópolis, Vozes.

ZUKIN, Sharon. (2000), "Paisagens urbanas pósmodernas: mapeando cultura e poder", in Antônio Arantes (org.), O espaço da diferença, Campinas, Papirus. 


\section{DE PERTO E DE DENTRO: NOTAS PARA UMA ETNOGRA- FIA URBANA \\ INSIDER AND A CLOSE-UP VIEW: NOTES ON URBAN ETHNOGRAPHY}

José Guilherme Cantor Magnani

\section{Palavras-chave}

Antropologia; Etnografia; Metrópole; Cultura urbana; Circuito

O texto busca pôr em relação duas linhas de análise, uma sobre cidade e outra sobre etnografia. O objetivo é discutir as possibilidades que este enfoque, próprio da antropologia, abre para o estudo da dinâmica urbana. Tomando como ponto de partida a apresentação de alguns quadros analíticos sobre o fenômeno urbano contemporâneo, caracterizados como um "olhar de fora e de longe", é desenvolvida a perspectiva da etnografia, chamada, por contraste, de um "olhar de perto e de dentro". Explicitados os pressupostos teóricos que sustentam essa posição, é apresentada uma estratégia de pesquisa com base nessa argumentação para, finalmente, mostrar seu uso em alguns exemplos etnográficos mais recentes. $\mathrm{O}$ argumento termina sinalizando que um olhar "distanciado" amplia e complementa a perspectiva proposta, possibilitando a articulação do recorte etnográfico, bem delimitado, com planos e modelos mais gerais de análise.
José Guilherme Cantor Magnani

\section{Keywords}

Anthropology; Ethnography; Metropolis; Urban culture; Circuit

By interrelating two lines of analysis, one having to do with the city and the other with ethnography, this paper seeks to discuss possibilities which are opened by an anthropological approach to the study of urban dynamics.Discussion of analytical charts for study of contemporary urban phenomena allows for a characterization of what may be termed as an "outsider and long-distanced view". A contrasting "insider and close-up view" is outlined.Theoretical presuppositions are explicated and research strategy is proposed. As a way o demonstration, recent ethnographic examples are used. Finally, it is suggested that a "distanced" view may effectively broaden and complement the proposed perspective, making possible an articulated project involving well delimited ethnographic research design and more general levels and models of analysis.

\section{DE PRÈS ET DE L'INTÉ- RIEUR: NOTES POUR UNE ETHNOGRAPHIE URBAINE}

José Guilherme Cantor Magnani

\section{Mots-clés}

Anthropologie; Ethnographie; Métropole; Culture urbaine; Circuit

Ce texte cherche à mettre en rapport deux courants d'analyse : celui consacré à la ville et celui consacré à l'ethnographie. Il a pour but de discuter les possibilités offertes par cette dernière, proprement anthropologique, à l'étude des dynamiques urbaines. Partant de la présentation de quelques cadres analytiques du phénomène urbain contemporain, caractérisés par un "regard de l'extérieur et de loin", on y développe la perspective ethnographique appelée, par contraste, "regard de près et de l'intérieur". Les fondements théoriques de ce courant étant présentés, une stratégie de recherche se présente, fondée sur ces arguments. Cette stratégie est ensuite utilisée sur des exemples ethnographiques plus récents. Nous suggérons, finalement, qu'un regard "éloigné" peut élargir et compléter la perspective proposée, rendant possible l'articulation d'un découpage ethnographique bien cerné et des plans et modèles d'analyse plus généraux. 